\title{
PSEUDOTUMOR INFLAMATORIO DE RIÑÓN
}

\author{
E.C. CARMONA CAMPOS*, A. LÓPEZ BELTRÁN** \\ *Servicio de Urología. Hospital Alto Guadalquivir. Andújar. Jaén. \\ **Patología. Hospital Regional Universitario Reina Sofia. Córdoba.
}

Actas Urol Esp. 27 (9): 739-741, 2003

\section{RESUMEN}

PSEUDOTUMOR INFLAMATORIO DE RIÑÓN

El pseudotumor inflamatorio es una rara lesión descrita en diversos órganos y de forma esporádica en vejiga y pelvis renal. Su etiología es desconocida y el comportamiento benigno, pero se debe establecer el diagnóstico diferencial con otras neoplasias como el leiomiosarcoma y el rabdomiosarcoma, lo que suele requerir del uso de técnicas de microscopía electrónica e inmunohistoquímica. El propósito de este artículo es presentar el segundo caso de pseudotumor inflamatorio a nivel intrarrenal.

PALABRAS CLAVE: Pseudotumor inflamatorio. Tumor miofibroblástico. Granuloma. Riñón.

\section{ABSTRACT}

\section{INFLAMMATORY PSEUDOTUMOR OF KIDNEY}

Inflammatory pseudotumours are rare lesions that may appear in several organs, and sporadically in the bladder and the renal pelvis. Aetiology is unknown and they show a non-malignant behaviour although differential diagnosis with other neoplasia such as leiomyosarcoma and rabdomyosarcoma must be established. Electron microscopy and immunohistochemistry are commonly used techniques to achieve diagnosis. The aim of this paper is to examine the second case report of intrarenal inflammatory pseudotumour.

KEY WORDS: Inflammatory pseudotumor. Myofibroblastic tumor. Granuloma. Kidney.

$\mathrm{E}_{\mathrm{l} s}^{1}$ granuloma de células plasmáticas es una lesión inflamatoria inespecífica inusual, benigna y de etiología desconocida, descrita en diversos órganos, y esporádicamente en vejiga. Reportamos un caso a nivel intrarrenal, suponiendo a nuestro entender el segundo caso descrito en dicha localización. Se describen las características patológicas de la lesión así como el diagnóstico diferencial.

\section{CASO CLÍNICO}

Varón de 66 años con varicocele. En el curso de una revisión se le practica una ecografía abdominal que muestra un tumor localizado en el polo inferior del riñón derecho con características de quiste complicado (Fig. 1). Se realiza TAC abdominal que describe una lesión exofítica, bien delimitada en tercio inferior del riñón derecho, de 4,4 x 3,6 cm de diámetro, con densidad superior al líquido e incremento de los valores densitométricos tras administración de contraste intravenoso; no se observan adenopatías (Fig. 2). La PAAF de la lesión no es concluyente por la escasez de material. Se realiza nefrectomía radical derecha. El examen macroscópico muestra una neoformación que sobresale del órgano, de $4 \mathrm{~cm}$, blanquecina, 


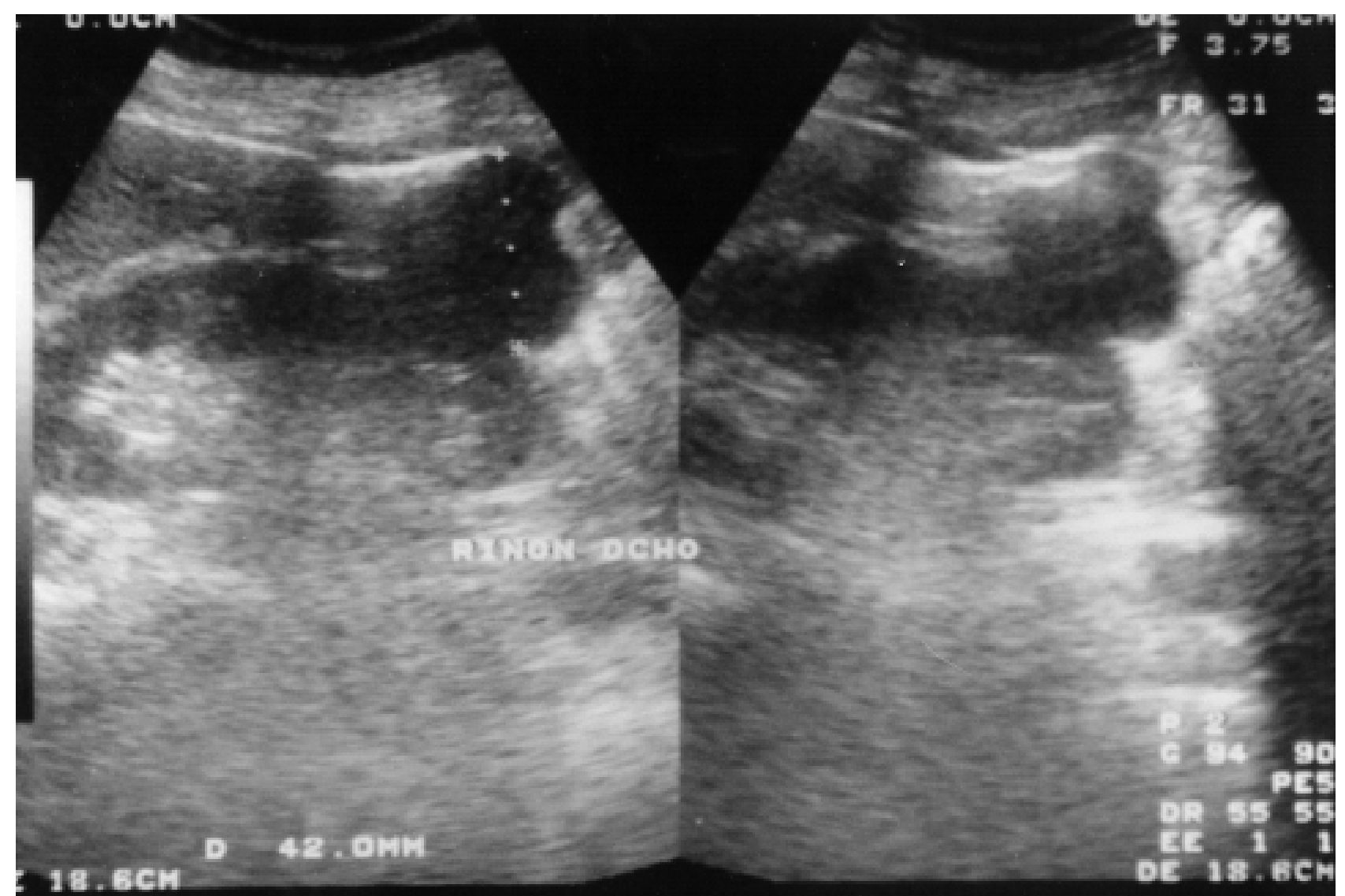

FIGURA 1

fascicular, y de consistencia elástica, bien delimitada del parénquima renal subyacente (Fig. 3). Histológicamente se trata de una lesión bien delimitada situada a nivel de la cápsula renal y compuesta de abundantes células plasmáticas maduras, con ocasionales linfocitos, dispuestos en acúmulos y ocasionalmente dispersas sobre un fondo de fibroblastos y miofibroblastos ocasionalmente multinucleados; y sin observarse extensión a parénquima renal. La aplicación de técnicas inmunohistoquímicas demuestra una población policlonal de células plasmáticas sobre un fondo fusocelular inmunoreactivo para vimentina. Otros marcadores tales como Actina, Desmina, CD34, S100 y Keratina fueron negativos. La microscopía electrónica muestra una población celular sugestiva de origen miofibroblástico. El diagnóstico anatomopatológico fue de granuloma de células plasmáticas (pseudotumor inflamatorio). Con un seguimiento de 36 meses el paciente permanece asintomático.

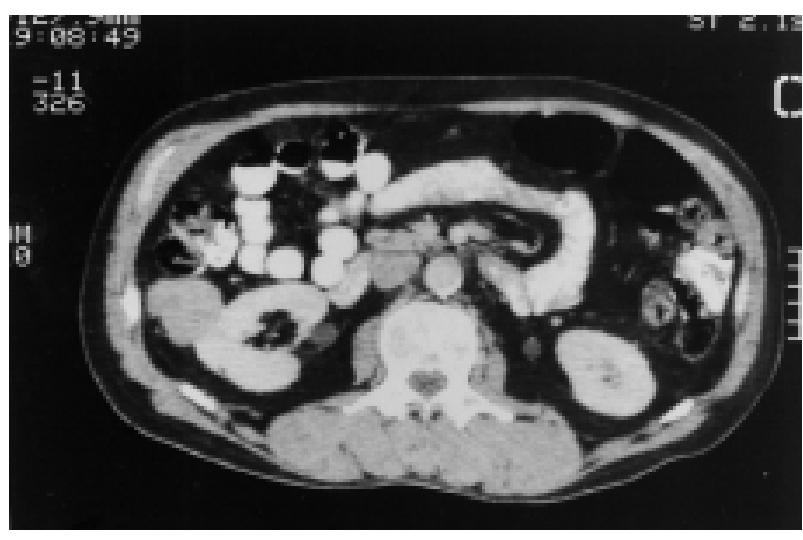

FIGURA 2

\section{COMENTARIOS}

El pseudotumor inflamatorio es una rara lesión benigna de etiología desconocida, descrita en diversos órganos, que se caracteriza por la proliferación localizada de fibroblastos y miofibroblastos asociados a un prominente infiltrado celular inflamatorio compuesto de células plas- 


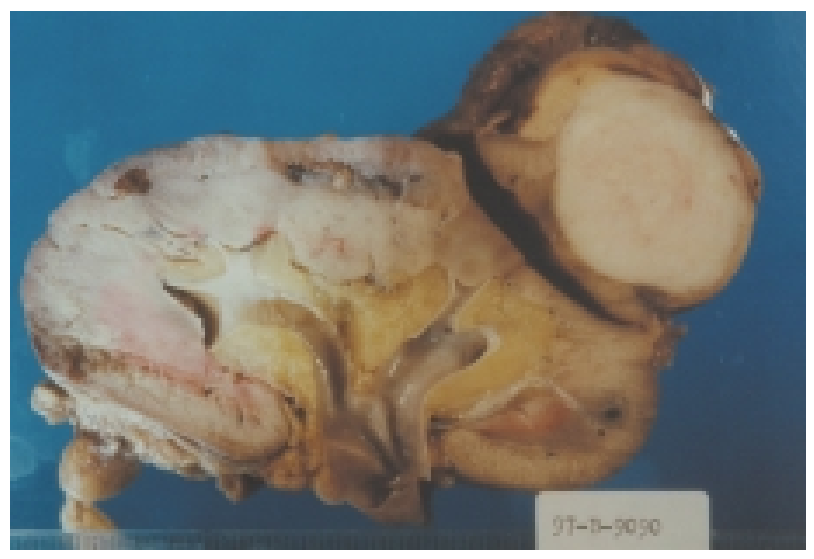

FIGURA 3

máticas, linfocitos e histiocitos, y ocasionalmente neutrófilos $\mathrm{y}$ eosinófilos ${ }^{1-3}$. Esta entidad ha sido descrita previamente con numerosos términos: granuloma de células plasmáticas, tumor fibromixoide pseudosarcomatoso, tumor fibromixoide atípico, tumor miofibroblástico inflamatorio, tumor miofibroblástico atípico y proliferación miofibroblástica pseudosarcomatosa ${ }^{3,4}$. En la actualidad se denomina más frecuentemente como pseudotumor inflamatorio o tumor miofibroblástico inflamatorio. Esta lesión que es más frecuente en pulmón, ha sido descrita esporádicamente en vejiga y excepcionalmente en pelvis renal, uréter y testículo ${ }^{5-8}$. Para nuestro entender sólo un caso similar ha sido reportado en riñón ${ }^{1}$. Histológicamente se trata de una lesión bien delimitada que se sitúa a nivel de la cápsula renal y que se compone de abundantes células plasmáticas maduras y ocasionales linfocitos, dispuestos en acúmulos sobre un fondo de fibroblastos y miofibroblastos que ocasionalmente exhiben multinucleación. El índice mitótico es muy bajo, y no se observa extensión al parénquima renal, no siendo características las mitosis atípicas, necrosis, alta celularidad y el crecimiento infiltrativo / destructivo ${ }^{1,3,7}$. La naturaleza neoplásica de la lesión se apoya en estudios moleculares que sugieren clonalidad en la celularidad proliferante. El diagnóstico diferencial histológico debe incluir el tumor fibroso solitario, el fibrohistiocitoma, el leiomioma, el fibrosarcoma, el carcinoma sarcomatoide y el angiomiolipoma ${ }^{2}$. De gran importancia para la correcta clasificación de la lesión es el uso de marcadores inmunohistoquímicos que incluyen la positividad para Vimentina y la policlonalidad del componente linfoplasmocitario mediante la detección de cadenas ligeras kappa y lambda, así como la negatividad para CD34, marcadores musculares e histiocitarios. También la microscopía electrónica es de gran importancia al demostrar la naturaleza miofibroblástica del componente fusocelular. El tratamiento consiste en la resección quirúrgica, postulando algunos autores un manejo agresivo debido al potencial para la destrucción local seve$\mathrm{ra}^{3}$. Son extremadamente raras las recurrencias y no han sido reportadas metástasis. Aunque las características clínico-patológicas de esta lesión indican su naturaleza benigna, la rareza de la misma y la semejanza histológica con diversas lesiones malignas recomiendan un seguimiento adecuado del paciente.

\section{REFERENCIAS}

1. FISCH A, BRODEY P.: Plasma cell granuloma of kidney. Urology 1976; 8: 89-91.

2. JONES E, CLEMENT P, YOUNG R.: Inflammatory pseudotumor of the urinary bladder: a clinicopathological, inmunohistochemical, ultraestructural, and flow cytometric study of 13 cases. Am J Surg Pathol 1993; 17: 264-274.

3. NETTO, JOSÉ MURILLO B., PÉREZ, LUIS M, KELLY, DAVID R, JOSEPH DAVID B.: Pediatric inflammatory bladder tumors: myofibroblastic and eosinophilic subtypes. J Urol 1999; 162: 1.424-1.429.

4. DAVIDES K et al.: Plasma cell granuloma of the renal pelvis. J Urol 1972; 107: 938.

5. ITOH H, NAMIKI M, YOSHIOKA T et al.: Plasma cell granuloma of the renal pelvis. $J$ Urol 1982; 127: 1.177-1.179.

6. LÓPEZ-BELTRÁN A, LÓPEZ RUIZ J, VICIOSO L.: Inflammatory pseudotumor of the urinary bladder. A clinico-pathologic analysis of two cases. Urol Int 1995; 55: 173-176.

7. PINAR KAYNAK AKSOY, HANDAN OZDEMIR, CEM AYGUN, MUHTESEM AGILDERE.: Plasma cell granuloma of the testis: unusual localization. $J$ Urol 2001; 166: 1.000 .

8. WEISER ADAM C, CHENG EARL Y.: Pseudosarcomatous myofibroblastic tmor of the distal ureter. $J$ Urol 1999; 161: 1.926-1.927.

Dr. E.C. Carmona Campos

Corredera de Capuchinos, $15-2^{\circ}$

23740 Andújar (Jaén)

(Trabajo recibido el 7 febrero de 2002) 